\title{
Prevalence and Effects of Sleep Disorders Among Shift Work Nurses
}

\author{
Mohammad-Rafi Bazrafshan ${ }^{1}$, Razzagh Rahimpoor ${ }^{2}$, Fatemeh Moravveji $^{3}$, Nasrin Soleymaninejad ${ }^{3}$, \\ Esmaeil Kavi ${ }^{1}$, Fatemeh Sookhak ${ }^{1}$ and Razieh Zolghadr ${ }^{4, *}$ \\ ${ }^{1}$ Department of Nursing, School of Nursing, Larestan University of Medical Sciences, Larestan, Iran \\ ${ }^{2}$ Department of Occupational Health, School of Public Health, Hamadan University of Medical Sciences, Hamadan, Iran \\ ${ }^{3}$ Department of Occupational Health, Ewaz School of Health, Larestan University of Medical Sciences, Larestan, Iran \\ ${ }^{4}$ Department of Public Health, Ewaz School of Health, Larestan University of Medical Sciences, Larestan, Iran \\ "Corresponding author: Assistant Professor, Department of Public Health, Ewaz School of Health, Larestan University of Medical Sciences, Larestan, Iran. Tel: +98-7152518346, \\ Fax: +98-7152518346, Email: raziezolghadr@yahoo.com
}

Received 2018 June 23; Revised 2018 October 09; Accepted 2018 October 26.

\begin{abstract}
Background: Sleep is one of the most basic and physiologic needs, which has impressive effects on the humans' physical and mental health. According to the need for permanent presence of the nurses in the hospitals, they often suffer from shift work effects such as sleep disorders.

Objectives: Considering the high sensitivity of nursing jobs, the aim of this study was to evaluate the prevalence and consequence of sleep disorders in shift work nurses.

Methods: This cross-sectional study was conducted on all of the nurses employed in hospitals of Larestan city in south of Iran in 2017. After screening based on inclusion criteria, 100 nurses were selected. to evaluate the prevalence and consequence of sleep disorders in the nurses, the Pittsburgh Sleep Quality Index (PSQI), Epworth Sleep Quality Index (ESQI) and Insomnia Severity Index (ISI) were used. Data were analyzed using SPSS software version16. Descriptive and analytical statistical tests, including One-way ANOVA, paired $t$-test, independent $t$-test, Kruskal-Wallis, chi-square, and Pearson correlation coefficient were used to analyze the data. A P $\leq 0.05$ was considered statistically significant.

Results: The results showed the mean score of sleep quality index was $6.52 \pm 4.23$ and according to this index, 56\% of the studied nurses are in hazardous situations. In all of the nurses, sings of insomnia were observed during routine works; consequently, $78.5 \%$ were sleepy, $16.5 \%$ were very sleepy, and $5 \%$ were severe sleepy. By the increased rate of night shift work per week, the severity of insomnia was also increased in the nurses $\left(\mathrm{R}^{2}=0.78\right)$. Sleep disorders in the nurses working in the surgical section were higher than the nurses in other sections of the hospitals $(\mathrm{P}<0.05)$.

Conclusions: A high percentage of the nurses employed in different sections of the hospitals have poor sleep quality and increased rate of night shift work per week plays a major role in decreasing their sleep quality. Regarding the adverse effects of poor sleep quality on the health status of the nurses and their quality of job performance, it is necessary to carry out proper planning to improve the sleep quality of night shift work nurses employed in different sections of the hospitals.
\end{abstract}

Keywords: Nurses, Shift Work, Sleep Disorders, Sleep Hygiene

\section{Background}

Sleep is one of the most important elements in nighttime cycles, which is associated with the reconstruction of physical and emotional powers. About a third of human life is devoted to sleep and more than $30 \%$ of the world population suffers from sleep disorders that are due to mental -psychological diseases, physical disease, second job, nocturnal work, etc $(1,2)$. Sleep quality is important from two aspects: The first is common complaint about the lack of high-quality sleep among the general people, such as frequently staying awake and lack of having deep sleep, and the second is the weakness of sleep quality of the people such as shortness of sleep time duration $(3,4)$.

One of the most important areas for sustainable health development in human societies is the health and care system that the nurses are considered the largest professional group in this therapeutic system 'therefore, nurses usually form $40 \%$ of the hospital employees and $55 \%$ of the total employees' costs is allocated to them (5-7). In the health and care system, the proportion of the people who work at night is more than those people working in other public service providing areas, so $36.9 \%$ of the hospital employees are night-working individuals and they are often nurses (8).

Nursing is inherently a stressful occupation that re- 
quires a relatively high physical and mental activity (9). There are several stressful situations in nursing profession that can cause problems, including dissatisfaction, low efficiency, and retirement. These situations cause physical and mental problems that lead to irreversible damages in nursing care system (10). Previous studies have shown that high stress in the nurses has reduced their quality of work life (QWL) (11).

Shift work disorder is defined as a sleep disorder characterized by insomnia or insomnia in a person's daily schedule (12). Working in night shift had been unlike human nature and will cause a variety of disorders in nighttime rhythm (biological clock or circadian rhythm) and other adverse health effects, including cardiovascular disorders, digestive disorders, reproductive system disorders, decreasing efficacy, and increasing the rate of accident in the employees $(13,14)$. The nature of the nursing job and their occupational stress, along with the harmful physical factors, cause sleep disorders and sleepiness during a day $(15,16)$.

Lack of sleep and inadequate sleep quality as one of the effects caused by shift work can lead to depression, lack of concentration, decreasing the function of the immune system, hypertension, cardiovascular risks, and reducing the activity and consciousness level of the people $(14,17)$. Several studies have shown that mortality rate in people with a sleep time less than 3.5 hours and more than 8.5 hours is higher than those people with a sleep duration of 7 hours a day. Also, the history of insomnia is considered one of the most important promising variables of depression occurrence, so people with no history of depression but suffering from sleep disorders have a risk of suffering from major depression in the future, roughly double of others. Therefore, nurses who do not have a strong public health will not be able to perform and provide physical and psychological support to their patients in a competent way, which this issue will increase the risk of mistakes and occurrence of occupational accidents, consequently its outcome will affect the patient and general public in addition to the nurses $(8,18-20)$.

Finally, disorder in the quality of sleep will disrupt the quality of nursing services, along with a delay in the patient's improvement process and depriving of suitable care services, will result in the reduction of the productivity and quality of performance related to the nurses. Thus the nurses must have a sleep quality and consequently the good quality of life in order to provide appropriate and suitable services $(21,22)$.

In a study by Flo et al. that conducted on shift work disorders in the nurses in 2012, it was found that sleepiness disorders, insomnia, and shift work symptoms are increased following the increment of nocturnal work in the nurses (12). A study that was conducted by Eldevik et al. in 2013 investigated the adverse effects of nocturnal work on the nurses, it was founded that the incidence rate of insomnia, too much sleepiness, excessive fatigue, and disorder in the rhythm of the circulatory cycle are increased in the nurses after changing the shift work (23).

In a study that was conducted by Khazaei et al. on sleep disorders among the nurses with shift work in hospitals of Iran, it was found that shift work increases daily dysfunctions due to lack of sleep, increased incidence of lack of sleep, and sleep apnea among the nurses. Moreover, it was found that sleep disorders among the nurses can affect the health of both patients and nurses (24). So far, various questionnaire-based methods have been used in various studies to investigate sleep disorders and severity of depression among employed people. the questionnaires of Epworth, Petersburg, and the Insomnia indices have high efficiency and high-performance precision in this field (2527).

Considering the nurses' job nature to the necessary work at night shift and subsequently increasing the probability of adverse health outcomes; this important issue, its aspects, and various pivotal factors of this problem has been less widely considered in Larestan. Furthermore, because of the failure to carry out a research study to investigate the physical and neuropsychological effects of night work in nurses in the southern part of the Iran, we don't have comprehensive information about sleep health status yet.

\section{Objectives}

This study was conducted to investigate the type and percentage of sleep disorders and their impacts among nurses in the night shift, to provide the grounds for greater attention of scholars to its different aspects, which may ultimately lead to providing satisfactory work conditions with minimum complications of sleep disorder among nurses.

\section{Methods}

\subsection{Study Design}

The present study is a cross-sectional (descriptiveanalytic) study that it was performed to evaluate the prevalence of sleep disorders and their adverse health effects among shift work nurses in the hospitals of the Larestan city. 


\subsection{Sampling}

All nurses with BA degree shift work were surveyed by census method sampling on a fixed day (07:30 to 13:30), afternoon (13:30 to 19:30) or (19:30 to 7:30) schedule studied in the hospitals of Larestan city. Finally, 100 nurses entered the study according to the inclusion criteria. The inclusion criteria were at least one-year work experience, lack of second job, no addiction to alcohol and caffeine, no history of mental diseases, and no history of family sleep disorder. The exclusion criteria were as follow second job, addiction to alcohol and caffeine, and mental illness.

\subsection{Instrument}

In this study, the data collection was done through face-to-face interview and the tools used in this study included four questionnaires: A: Researcher-made questionnaire of demographic information of the nurses; B: Pittsburgh Sleep Quality Standard Index (PSQI) to assess sleep quality; C: Epworth Sleep Quality Index (ESQI) questionnaire to assess the 'daytime sleepiness'; and D: Insomnia Severity Index (ISI) questionnaire to evaluate insomnia. Demographic information of the studied nurses such as age, gender, marital status, educational level, the number of children, type of employment status, and the number of night work shifts per week were collected using researcher-made questionnaire of demographic information. Using 19 questions the following situations were recorded: Sleep mental quality, required time duration to sleep, useful sleep duration, sleep disorder, daily dysfunction and use of the sleep medications In the PSQI questionnaire. In this questionnaire, 19 questions were scored in a 4-point Likert scale from 0 to 3, the zero score indicated lack of sleep problem, the score 1 indicated medium problem in the sleep, the score 2 indicated a serious problem in the sleep, a score 3 indicated a very serious problem in the sleep. Also, getting a total score of over 5 in the entire questionnaire meant poor sleep quality. Data related to the sleep status of the people during doing daily works and leisure time were collected using the ESQI questionnaire using 8 questions. In this questionnaire, according to the response of each section, a score was allocated to that part which ultimately determined the total score of the sleep pattern of nurses, scores less than 10 were sleepy, between 10 to 16 were very sleepy people and a score of more than 16 were dangerously sleepy. Data related to the sleep disorder, very early awakening, satisfaction with their sleep patterns and also creating the disorder in the person's life due to sleep problems were collected using the ISI questionnaire using 7 questions. The score of each nurse was determined (in the range of 0 to 28), which ultimately were classified in the four groups of no clinically significant insomnia $(0-7)$,
Sub-threshold insomnia ( 8 - 14), moderate clinical insomnia (15 - 21) and severe clinical insomnia (22 - 28). In order to diminish the nurses' bias in answering to the questionnaires, data were collected in different shift- works and various days of the week.

Content and formal verification method based on the resources and opinion polls of the faculty members were used to determine the validity of the information gathering tools. The internal consistency method was used to determine the reliability of PSQI, ESQI, and ISI.The Cronbach's Alpha coefficient for PSQI, ESQI, and ISI were 83\%, 87\%, and $91 \%$, respectively.

\subsection{Ethical Considerations}

The study protocol and its ethical considerations were approved by the applied research council and ethics committee of Larestan University of Medical Sciences (grant no. 139506). Permission was obtained from the hospital authorities and the purpose of the study was explained to all participants and they all signed the written informed consents before participation in this study. They were also assured of the data confidentiality and all the questionnaires were kept anonymous.

\subsection{Data Analysis}

Data of the study were entered in SPSS software version 16. Descriptive and analytical statistical tests such as One-way ANOVA, paired $t$-test, independent $t$-test, KruskalWallis, chi-square, and Pearson correlation coefficient were used to analyze the data. A P $\leq 0.05$ was considered statistically significant.

\section{Results}

Mean and standard deviation of the age and work history of studied nurses was $30.4 \pm 7.5$ and $7.4 \pm 7.12$, respectively. One hundred studied nurses were categorized into 49 females and 51 males according to gender. The minimum, the maximum, and average numbers of the nurses' night shift work were 1,8 , and 2 shifts per week. The demographic characteristics of the studied nurses were shown in Table 1.

The results of this study showed that the mean \pm standard deviation (SD) of the required time to fall sleep in the studied nurses after going to bed was $40.1 \pm 32.5$ minutes. The mean \pm SD of PSQI in the nurses was $6.52 \pm 4.23$. The results of this study showed that the sleep quality index of the nurses in different units of the hospital was significantly different from each other $(\mathrm{P}=0.04)$. The score of PSQI questionnaire of the nurses were categorized based on their occupational units in the hospital (Table 2). 


\begin{tabular}{lcc}
\hline \multicolumn{3}{l}{ Table 1. The Demographic Characteristics of the Studied Nurses } \\
\hline Variable & Number & Percentage \\
\hline Marital status & & \\
\hline Single & 43 & 40 \\
\hline Married & 57 & 60 \\
\hline Education level & & \\
\hline Associated & 22 & 22 \\
\hline BSc & 65 & 65 \\
\hline MSc & 13 & 13 \\
\hline Employment status & & \\
\hline Official & 22 & 17.14 \\
\hline Contractual & 44 & 48.57 \\
\hline Internship & 34 & 34.28 \\
\hline
\end{tabular}

The results also showed that sleep quality indices related to $44 \%$ of the nurses were in a good range (less than 5) whereas it was in a poor range (above 5) in 56\% of them. The results showed that there is a significant difference between the mean scores of the nurses' PSQI questionnaires according to their genders and the mean score in males and females was 7.3 and 4.8 , respectively $(\mathrm{P}=0.004)$.

The results related to the ESQI questionnaire revealed that of nurses working in different parts of the hospital, $78.5 \%$ had sleepiness, $16.5 \%$ had very sleepiness and $5 \%$ of them had symptoms of dangerous sleepiness. The results showed that there is a significant difference between the score of the index of Epworth sleepiness in the nurses categorized base on their gender, the mean and standard deviation of the raw scores of the ESQI questionnaire in the studied males and females were $11.3 \pm 4.9$ and $6.4 \pm 3.9$, respectively $(\mathrm{P}=0.02)$. The mean scores of the ESQI questionnaire related to the nurses studied based on occupational units categorized base on their gender were shown in Figure1. In the present study, it was determined there is a significant relationship between the number of nurses' night shift in a week and the mean scores of the ESQI questionnaire, so the mean score of the ESQI questionnaire will also be increased after increasing the number of night shift nurses in a week $\left(\mathrm{R}^{2}=0.78\right)$.

The results related to the ISI indicated that $46.4 \%$ of the people had poor insomnia, $45 \%$ had below the threshold insomnia and $8.6 \%$ of the studied nurses suffered from poor insomnia. The results of the score of ISI based on the occupational unit of the nurses revealed that the highest level of insomnia is was related to the nurses in the surgery unit and the lowest score is for the nurses of the internal medicine unit (7.5 \pm 4.3 and $13.3 \pm 5.7$, respectively). Based on the occupational unit of the nurses, the mean scores of the ISI were shown in Figure 2. The results of this study showed that gender differences did not have a significant effect on the score of the ISI of the studied nurses' ( $\mathrm{P}=$ 0.2 ). Also, the results of this study showed that the mean score index of the nurses increased by increasing the number of night shift work of the nurses per week $\left(R^{2}=0.76\right)$. The results related to the variables studied in the ISI questionnaire showed that $76.4 \%$ of the people had problem in sleeping, 59.4\% of the people had problem in staying slept and $63.8 \%$ of them had problem in early waking up. It was also found that $91.3 \%$ of the studied nurses are dissatisfied with their sleep pattern and $82.6 \%$ of them believed that the existence of sleep problem has interrupted their daily performance.

\section{Discussion}

Shift work can reduce sleep quality and the occurrence of sleep disorders among employees (28). The results of this study showed that increased rate of night shift among nurses increased the incidence of sleep disorders and decreased their sleep quality.

The results of the Pittsburgh Sleep Quality Index (PSQI) showed that $56 \%$ of the studied nurses had poor sleep quality (score above 5). In consistent with this study, it was reported in a study conducted by Gomez et al. in Spain that PSQI Score in nurses with night work shift is 6.8 (as the poor quality range). This score is considerably less among nurses with day work shift (29). Work rotation or shift work on different days of the week greatly increases the prevalence of sleep disorders. As a result, workers such as nurses have a feeling of sleepiness and discomfort in their work environment, which reduces the quality of preparing health services to patients and increases the risk of occupational errors. Considering the need for night presence of the nurses in hospital environments, these employees must enter to the shift work program, so hospital administrators must consider the guidelines and limits for the high number of night work shifts of the nurses per week in order to minimize the adverse health effects of shift work.

In this study, it was shown the poor sleep quality and the highest score for the PSQI questionnaire were related to the surgery units of the nurses (11.5) (Table 2), which may be due to high occupational stress of this work unit. In fact, high work stress increases fatigue and ultimately the need for the rest is increased and without the compensation of this work-related fatigue, the adverse health effects such as the prevalence of sleep disorders in night work shift nurses in stressful units will be higher than other parts of the hospital. In a similar study, it was indicated in the study of Eldevik et al. that increasing fatigue and work stress in the nurses reduced their sleep quality (23). Also, the results 


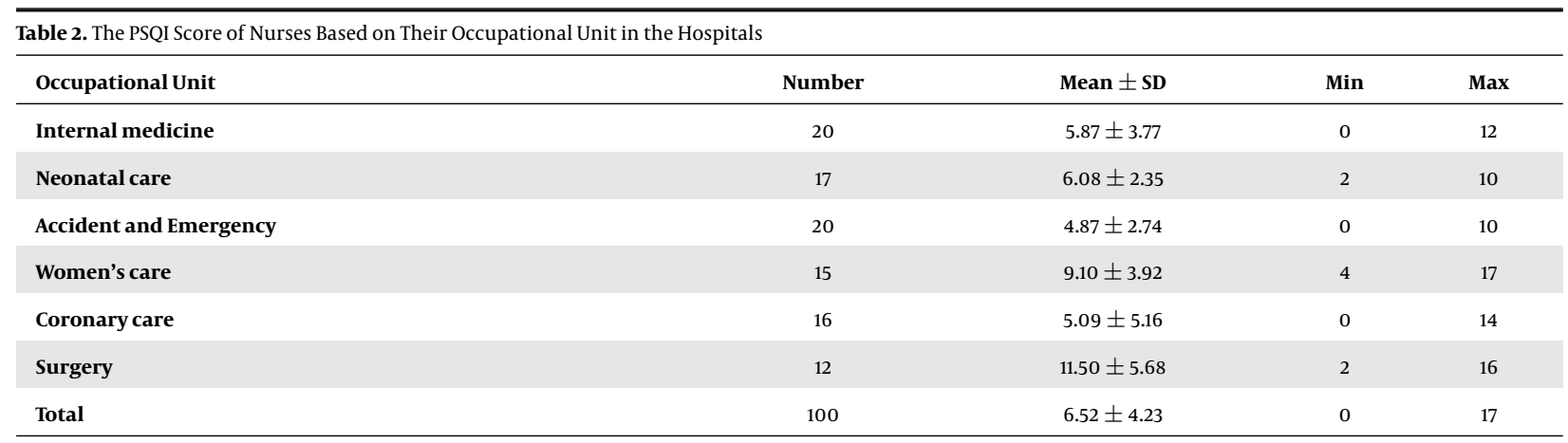

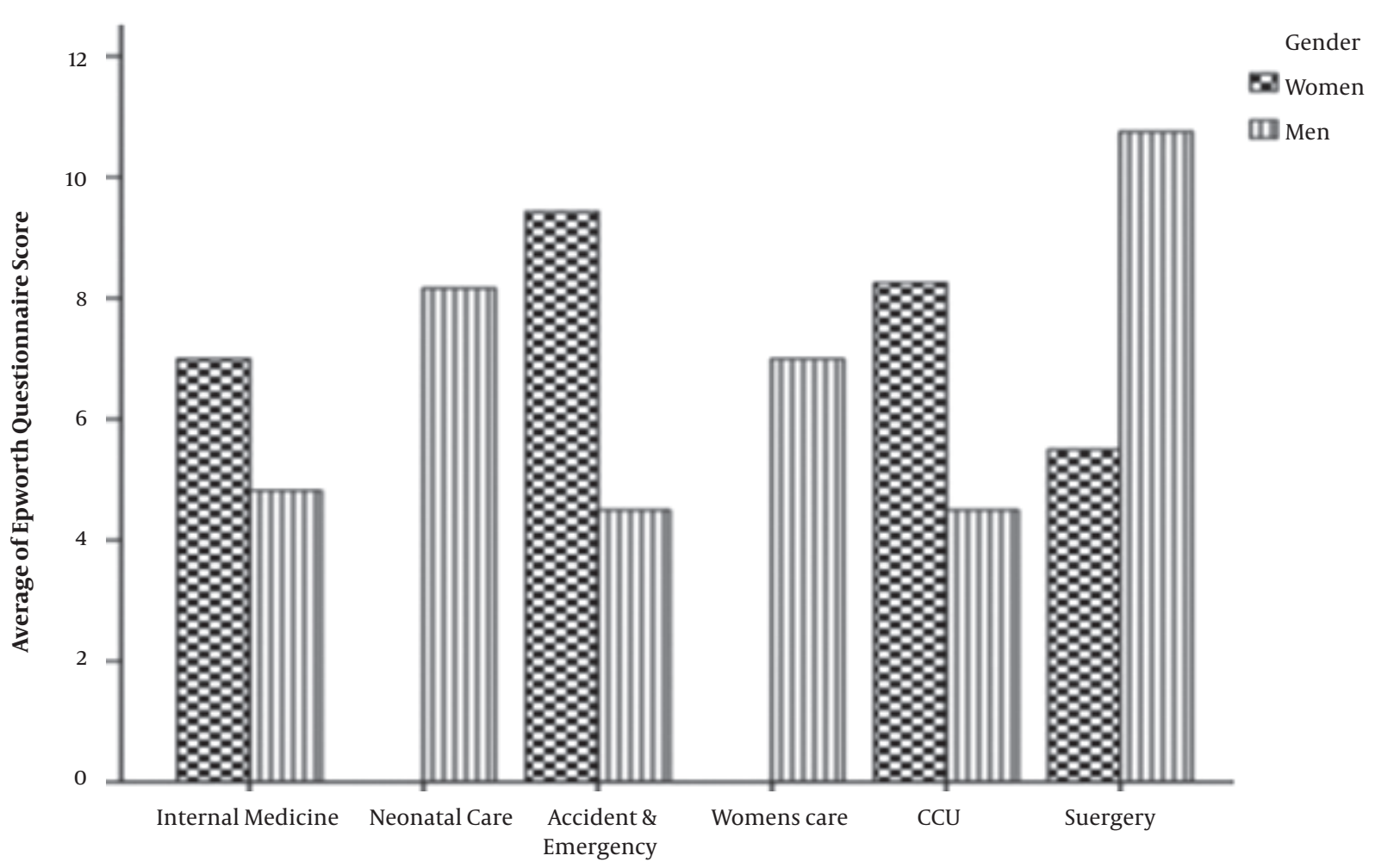

Name of Occupational Unit

Figure 1. The average of Epworth questionnaire score in nurses

of this study showed that the level of sleep quality in female nurses is significantly less than men, which could be due to the women's weaker body structure and the sensitivity of the women's psychological structure in comparison to the men. This finding is consistent with the previous studies, which investigated the correlation between some demographic factors and sleep disturbance and it has been reported that sleep disturbance is more common in women than men. It could be as a result of high sensitivity of the women to stress and sleep problems $(30,31)$. Gen- erally, home is a place for relaxation and stress relief from the outside world. This is true for most men, and children; however, for most women, as long as they are awake (sometimes even in their sleep), home is a workplace and this issue indirectly affects the care provided for the patients. This condition of women should be considered and compulsory overtime shifts for the women should be avoided in order to provide safe patient care $(32,33)$.

Based on the results of the ESQI questionnaire, it was determined that there is one of the sleepiness symptoms in 


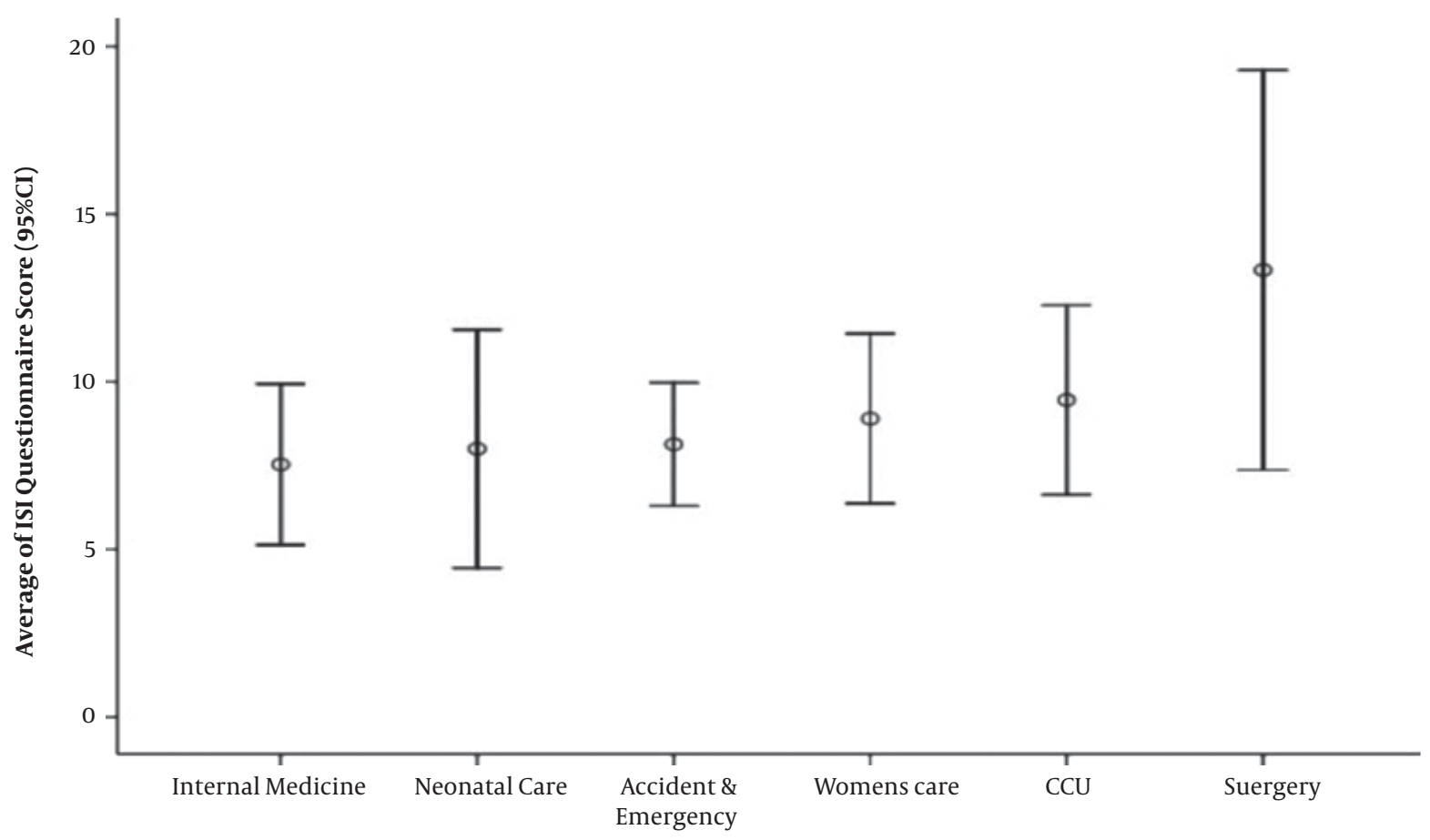

Name of Occupational Unit

Figure 2. The average of ISI questionnaire score in nurses based on their occupational unit

all studied nurses during doing their routine work or their leisure time, which presents sleep disorders in the studied nurses. According to a study done by Flo et al. on a1968 nurses, the results of the ESQI questionnaire indicated the existence of severe sleep disorders in $40 \%$ of the nurses, which had a direct relationship with the changeable shift program and the number of shift works at nights (12). As it was shown in Figure 2, the mean of raw score in female nurses is much higher than male nurses. This is in situations that the mean number of shift work nurses showed no significant difference between male and female night shift work and this higher difference score of sleep disorders in female nurses can be related to the higher activity of women at home than men and thus the time that they can rest at home is reduced. The results of this study showed that the highest score of the ESQI questionnaire is related to the nurses of the surgery unit.

Other results from ESQI questionnaire showed that after increasing the number of nurses' night shift works in a week, the score of ESQI questionnaire and consequently sleep disorders are increased $\left(\mathrm{R}^{2}=0.78\right)$. In a study by Zhen Lu et al. it was found that after increasing the shift work change and the number of nurses' night shift works sleep disorders rate $(\mathrm{P}<0.001)$, anxiety $(\mathrm{P}<0.001)$, depression $(\mathrm{P}<0.002)$ and their physical pain $(\mathrm{P}<0.001)$ were increased (34). In the study of Asaoka et al. conducted on the nurses in Japan, it was also reported that after increasing the nurses' night shift works, their job performance was significantly reduced and the incidence of cardiovascular disorders among them was increased (35).

The results of the ISI questionnaire showed that more than $55 \%$ of the studied nurses suffered from moderate to very high levels of insomnia that could be a danger alarm to the nursing society in order to prevent from the effects of insomnia on the health of the nurses and improve the quality of prepared health serviced to patients. In this regard, it was reported in a study that was conducted by Yazdi et al. on the nurses of Qazvin hospitals the prevalence of insomnia was high among 160 nurses (36). they found that there is a linear and direct relationship between sleepless severity of the nurses and the number of nursing shift work, so the severity of insomnia was increased in the nurses $\left(R^{2}=0.76\right)$ with the increase in the number of shift works per week. Similarly, Yazdi et al. showed that 
the number of nurses' night shift works had a significant effect on insomnia severity of the nurses $(P<0.05)$ (36). Among the common problems of the nurses, we can mention problems that are associated with sleeping, including problem in staying sleeping, irregular sleep pattern, and problem in enjoying a deep sleep. In fact,these problems are considered the most common problems in the people with sleep disorders and shift work. The physiological function and rhythm of the body's circadian system will be changed following by work hours in the outside (between 7 - $16 \mathrm{~h}$ a day), which will disrupt the secretion of body hormones, particularly the cortisol, aldosterone, and melatonin hormones (the hormones that regulate sleep and awakening of humans, which are secreted from the adrenal and pineal glands, respectively) and ultimately leads to sleep disorders and other adverse health effects in shift workers, especially the nurses (37).

\subsection{Conclusions}

Finally, it can be concluded that sleep problems are common among the nurses working in night shifts. There is a direct and linear relationship between the number of night shift works in a week and the prevalence of the sleep disorders such as poor quality of sleep, sleepiness in doing daily activities and leisure time, severity of insomnia, problem of sleeping, problem the staying in sleep, disorder in sleep pattern, and sleep mental dissatisfaction among the nurses. The prevalence of sleep disorders is higher among the nurses working in high-stressed units of the hospital such as surgery unit compared with the other nurses. Regarding the results of this study, in order to reduce the sleep disorders, reduce occupational errors, promote the health level of the hardworking nurses of the community and increase the quality of health services to the patients hospitalized in the hospitals as a vulnerable group of the community, it is recommended that officials of the nurse community and managers of the hospitals provide new solutions in their agenda to reduce and control the number of night shift works of the nurses in a working week.

\subsection{Strengths and Limitations}

In the present study, we used standardized and wellvalidated instruments. As the present study was crosssectional, it is difficult to conclude causal directions. Additionally, the study was not based on a large sample of shift workers, so the study aims may be influenced by possible confounding variables (i.e. different workload, environment, work schedule, etc.).

\section{Footnotes}

Authors' Contribution: All authors participated in various research stages.

Conflicts of Interests: There are no conflict of interests in financial issues with any individual or third party.

Ethical Considerations: The study protocol and its ethical considerations were approved by the applied Research Council and Ethics Committee of Larestan University of Medical Sciences (grant no. 139506). Permission was obtained from the hospital authorities and the purpose of the study was explained to all participants and they all signed the written informed consents before participation in this study. They were also assured of the data confidentiality and all the questionnaires were kept anonymous.

Funding/Support: The current study was financially supported by Larestan University of Medical Sciences, Larestan, Iran.

\section{References}

1. Suzuki K, Ohida T, Kaneita Y, Yokoyama E, Uchiyama M. Daytime sleepiness, sleep habits and occupational accidents among hospital nurses. J Adv Nurs. 2005;52(4):445-53. doi: 10.1111/j.13652648.2005.03610.x. [PubMed: 16268848].

2. Salehi K, Alhani F, Mahmoudifar Y, Rouhi N. [Quality of sleep and related factors among Imam Khomeini hospital staff nurses]. Iran J Nurs. 2010;23(63):18-25. Persian.

3. Buysse DJ, Reynolds CF 3rd, Monk TH, Berman SR, Kupfer DJ. The Pittsburgh Sleep Quality Index: A new instrument for psychiatric practice and research. Psychiatry Res. 1989;28(2):193-213. [PubMed: 2748771].

4. Dewald JF, Meijer AM, Oort FJ, Kerkhof GA, Bogels SM. The influence of sleep quality, sleep duration and sleepiness on school performance in children and adolescents: A meta-analytic review. Sleep Med Rev. 2010;14(3):179-89. doi: 10.1016/j.smrv.2009.10.004. [PubMed: 20093054].

5. Memarian R, Beigzadeh S. Application of nursing concepts and theories. Tehran: Asare Elmi Publication; 1999.

6. Shoghi M, Sanjari M, Shirazi F, Heidari S, Salemi S, Mirzabeigi G. Workplace violence and abuse against nurses in hospitals in Iran. Asian Nurs Res (Korean Soc Nurs Sci). 2008;2(3):184-93. doi: 10.1016/S19761317(08)60042-0. [PubMed: 25031253].

7. Hall LMG, Doran D, Pink GH. Nurse staffing models, nursing hours, and patient safety outcomes. J Nurs Admin. 2004;34(1):41-5. doi: 10.1097/00005110-200401000-00009.

8. Lin SH, Liao WC, Chen MY, Fan JY. The impact of shift work on nurses' job stress, sleep quality and self-perceived health status. J Nurs Manag. 2014;22(5):604-12. doi: 10.1111/jonm.12020. [PubMed: 25041800].

9. McNeely E. The consequences of job stress for nurses' health: Time for a check-up. Nurs Outlook. 2005;53(6):291-9. doi: 10.1016/j.outlook.2005.10.001. [PubMed:16360700].

10. Shahraki Vahed A, Mardani Hamuleh M, Sancholi J, Hamedi Shahraki S. [Assessment of the relationship between mental health and job stress among nurses]. J Jahrom Univ med sci. 2010;8(3):34-40. Persian. doi: $10.29252 / j m j .8 .3 .34$.

11. Khaghanizadeh M, Ebadi A, Cirati Nair M, Rahmani M. The study of relationship between job stress and quality of work life of nurses in military hospitals. J Mil Med. 2008;10(3):175-84. 
12. Flo E, Pallesen S, Mageroy N, Moen BE, Gronli J, Hilde Nordhus I, et al. Shift work disorder in nurses-assessment, prevalence and related health problems. PLoS One. 2012;7(4). e33981. doi: 10.1371/journal.pone.0033981. [PubMed: 22485153]. [PubMed Central: PMC3317447].

13. Harrington JM. Health effects of shift work and extended hours of work. Occup Environ Med. 2001;58(1):68-72. doi: 10.1136/oem.58.1.68.

14. Puttonen S, Harma M, Hublin C. Shift work and cardiovascular disease-pathways from circadian stress to morbidity. Scand J Work Environ Health. 2010;36(2):96-108. [PubMed: 20087536].

15. Azad E, Fathhi Ashtiani A, Ahmadi K. [Evaluation of stress in military personnel of Persian Gulf]. J Mil Med. 2007;8(4):249-54. Persian.

16. Ruggiero JS, Redeker NS. Effects of napping on sleepiness and sleeprelated performance deficits in night-shift workers: A systematic review. Biol Res Nurs. 2014;16(2):134-42. doi: 10.1177/1099800413476571. [PubMed: 23411360]. [PubMed Central: PMC4079545].

17. Ayas NT, White DP, Manson JE, Stampfer MJ, Speizer FE, Malhotra A, et al. A prospective study of sleep duration and coronary heart disease in women. Arch Intern Med. 2003;163(2):205-9. [PubMed: 12546611].

18. Learthart S. Health effects of internal rotation of shifts. Nurs Stand. 2000;14(47):34-6. doi: 10.7748/ns2000.08.14.47.34.c2895. [PubMed: 11974375].

19. Ghoreishi S, Aghajani A. Nursing students' quality of sleep in Zanjan. J Tehran Med Fac. 2009;66(1):61-7.

20. Wang XS, Armstrong ME, Cairns BJ, Key TJ, Travis RC. Shift work and chronic disease: The epidemiological evidence. Occup Med (Lond). 2011;61(2):78-89. doi: 10.1093/occmed/kqr001. [PubMed: 21355031]. [PubMed Central: PMC3045028].

21. Muecke S. Effects of rotating night shifts: Literature review. J Adv Nurs. 2005;50(4):433-9. doi: 10.1111/j.1365-2648.2005.03409.x. [PubMed: 15842451]

22. Caruso CC. Negative impacts of shiftwork and long work hours. Rehabil Nurs. 2014;39(1):16-25. doi: 10.1002/rnj.107. [PubMed: 23780784]. [PubMed Central: PMC4629843].

23. Eldevik MF, Flo E, Moen BE, Pallesen S, Bjorvatn B. Insomnia, excessive sleepiness, excessive fatigue, anxiety, depression and shift work disorder in nurses having less than 11 hours in-between shifts. PLoS One. 2013;8(8). e70882. doi: 10.1371/journal.pone.0070882. [PubMed: 23976964]. [PubMed Central: PMC3744484].

24. Khazaei H, Chehri A, Naghshbandy E, Tahmasian M. [The Comparison of sleep Disorders among shift workers and non-shift workers in Kermanshah Hospital (2005)].J Kermanshah Univ Med Sci. 2013;16(8):6506. Persian.

25. Farrahi Moghaddam J, Nakhaee N, Sheibani V, Garrusi B, Amirkafi A. Reliability and validity of the Persian version of the pittsburgh sleep quality index (PSQI-P). Sleep Breath. 2012;16(1):79-82. doi: 10.1007/s11325-010-0478-5. [PubMed: 21614577].

26. Ulasli SS, Gunay E, Koyuncu T, Akar O, Halici B, Ulu S, et al. Predic- tive value of Berlin Questionnaire and Epworth Sleepiness Scale for obstructive sleep apnea in a sleep clinic population. Clin Respir J. 2014;8(3):292-6. doi: 10.1111/crj.12070. [PubMed: 24188527].

27. Arakane M, Castillo C, Rosero MF, Penafiel R, Perez-Lopez FR, Chedraui $P$. Factors relating to insomnia during the menopausal transition as evaluated by the insomnia severity index. Maturitas. 2011;69(2):157-61. doi: 10.1016/j.maturitas.2011.02.015. [PubMed: 21444163].

28. Ohayon MM, Lemoine P, Arnaud-Briant V, Dreyfus M. Prevalence and consequences of sleep disorders in a shift worker population. J Psychosom Res. 2002;53(1):577-83. [PubMed: 12127174].

29. Gomez-Garcia T, Ruzafa-Martinez M, Fuentelsaz-Gallego C, Madrid JA Rol MA, Martinez-Madrid MJ, et al. Nurses' sleep quality, work environment and quality of care in the Spanish National Health System: Observational study among different shifts. BMJ Open. 2016;6(8) e012073. doi: 10.1136/bmjopen-2016-012073. [PubMed: 27496241]. [PubMed Central: PMC4985858].

30. Sepehrmanesh Z, Mousavi G, Saberi H, Saei R. Sleep quality and related factors among the nurses of the Hospital of Kashan University of Medical Sciences, Iran. Int Arch Health Sci. 2017;4(1):17. doi: 10.4103/iahs.iahs_8_17.

31. Oginska H, Pokorski J. Fatigue and mood correlates of sleep length in three age-social groups: School children, students, and employees. Chronobiol Int. 2006;23(6):1317-28. doi: 10.1080/07420520601089349. [PubMed: 17190716].

32. Kazemi M, Hosieni F, Rezaeian M, Fasihih T, Akbary A. Factors associated with quality of sleep of nurses at Rafsanjan University of Medical Sciences, Iran, in 2013. JOccup Health Epidemiology. 2015;4(1):26-33. doi: 10.18869/acadpub.johe.4.1.26.

33. Zhang L, Sun DM, Li CB, Tao MF. Influencing factors for sleep quality among shift-working nurses: A cross-sectional study in China using 3-factor pittsburgh sleep quality index. Asian Nurs Res (Korean Soc Nurs Sci). 2016;10(4):277-82. doi: 10.1016/j.anr.2016.09.002. [PubMed: 28057314].

34. Zhen Lu W, Ann Gwee K, Yu Ho K. Functional bowel disorders in rotating shift nurses may be related to sleep disturbances. Eur J Gastroenterol Hepatol. 2006;18(6):623-7. [PubMed:16702851].

35. Asaoka S, Aritake S, Komada Y, Ozaki A, Odagiri Y, Inoue S, et al Factors associated with shift work disorder in nurses working with rapid-rotation schedules in Japan: The nurses' sleep health project. Chronobiol Int. 2013;30(4):628-36. doi: 10.3109/07420528.2012.762010. [PubMed: 23445510].

36. Yazdi Z, Sadeghniiat-Haghighi K, Javadi AR, Rikhtegar G. Sleep quality and insomnia in nurses with different circadian chronotypes: Morningness and eveningness orientation. Work. 2014;47(4):561-7. doi: 10.3233/WOR-131664. [PubMed: 23823210]

37. Reinberg A, Ashkenazi I. Internal desynchronization of circadian rhythms and tolerance to shift work. Chronobiol Int. 2008;25(4):62543. doi: 10.1080/07420520802256101. [PubMed: 18622820]. 